\title{
One-Step Assembly of Coordination Complexes for Versatile Film and Particle Engineering
}

\author{
Authors: Hirotaka Ejima, Joseph J. Richardson, Kang Liang, James P. Best, Martin P. van \\ Koeverden, Georgina K. Such, Jiwei Cui, Frank Caruso*
}

\begin{abstract}
Affiliations:
Department of Chemical and Biomolecular Engineering, The University of Melbourne, Parkville, Victoria 3010, Australia.

*To whom correspondence should be addressed. E-mail: fcaruso@unimelb.edu.au (F.C.)

Abstract: The development of facile and versatile strategies for thin film and particle engineering is of immense scientific interest. However, few methods can conformally coat substrates of different composition, size, shape, and structure. Herein, we report the one-step coating of various interfaces using coordination complexes of natural polyphenols and $\mathrm{Fe}$ (III) ions. Film formation is initiated by the adsorption of the polyphenol and directed by $\mathrm{pH}-$ dependent, multivalent coordination bonding. Aqueous deposition is performed on a range of planar as well as inorganic, organic, and biological particle templates, demonstrating an extremely rapid technique for producing structurally-diverse, thin films and capsules that can disassemble. The ease, low-cost, and scalability of the assembly process, combined with $\mathrm{pH}$ responsiveness and negligible cytotoxicity, makes these films potential candidates for biomedical and environmental applications.
\end{abstract}

Main Text: Advances in materials design and application are highly dependent on the development of versatile thin film and particle engineering strategies (1-4). Supramolecular metal-organic thin films have attracted widespread interest due to their diverse properties, which include: (i) stimuli-responsiveness imparted by the dynamic nature of supramolecular coordination bonds; (ii) hybrid physicochemical properties of both metals and organic materials; and (iii) controlled structure and functionality achieved by variation of the molecular building blocks $(5,6)$. Although metal-organic thin films show potential for sensing, separation processes and catalysis $(5,6)$, such films are fabricated with multiple, time-consuming steps (7-11). Moreover, biomedical applications of these films have thus far been limited because they are typically unstable in water or are toxic (12).

Herein, we report a simple, rapid, and robust conformal coating method using the onestep assembly of coordination complexes on a range of substrates to prepare various films and particles. The natural polyphenol, tannic acid (TA) and $\mathrm{Fe}^{\mathrm{III}}$ were chosen as organic ligands and inorganic cross-linkers, respectively. Film deposition occurs upon mixing TA and Fe ${ }^{\mathrm{III}}$ in water at ambient temperature. No special equipment is necessary for this method, and the material components are readily and economically available. Moreover, they are generally recognized as safe (GRAS) by the United States Food and Drug Administration. Although the chemical structure of TA is usually given as a decagalloyl glucose $\left(\mathrm{C}_{76} \mathrm{H}_{52} \mathrm{O}_{46}\right)$ [fig. S1 (13)], it is actually a mixture of polygalloyl glucose molecules with different numbers of esterified gallic acid (14). Three galloyl groups from TA can react with each $\mathrm{Fe}^{\mathrm{III}}$ ion to form a stable octahedral complex (15), allowing each TA molecule to react with several Fe $\mathrm{Fe}^{\mathrm{III}}$ centers to form a cross-linked film. This method is applicable to a wide variety of substrates because of the general surface binding 
affinity of TA. When these films are deposited on particles, subsequent dissolution of the templates results in the formation of three-dimensional free-standing films known as hollow capsules, systems that have widespread use in drug and gene delivery, catalysis, biosensing, and as microreactors (16).

We first describe the deposition of $\mathrm{Fe}^{\mathrm{III}} / \mathrm{TA}$ films on planar (Fig. 1A) and particulate (Fig. 1, B to K) polystyrene (PS) templates. The color of the template suspension immediately turned blue upon addition of $\mathrm{Fe}^{\mathrm{III}}$ and TA solutions (fig. S2). Stirring times (20 sec and $1 \mathrm{~h}$ ) had no effect on the color or on the resulting film thickness under standard conditions (13), implying that the film formation process was completed instantaneously. Formation of the Fe $\mathrm{F}^{\mathrm{III}} / \mathrm{TA}$ films on the PS particles shifted the surface zeta-potential from $-27.4 \pm 2.8$ to $-64.0 \pm 6.9 \mathrm{mV}$ due to the acidic nature of the galloyl groups in TA. After removing the PS template, we obtained highly uniform microcapsules with a zeta-potential of $-64.6 \pm 7.3 \mathrm{mV}$, which was approximately the same value as before template removal.

Differential interference contrast (DIC) microscopy, atomic force microscopy (AFM), scanning electron microscopy (SEM), and transmission electron microscopy (TEM) images of the $\mathrm{Fe}^{\mathrm{III}} / \mathrm{TA}$ capsules are shown in Fig. 1, B to E. Monodisperse, spherical capsules were readily observed under DIC (Fig. 1B). The permeability of these capsules is molecular weight dependent, and they are essentially impermeable to 2,000 kDa dextran (fig. S3). The presence of $\mathrm{Fe}$ in the films was confirmed by energy dispersive X-ray spectroscopy (EDS) (fig. S4) and Xray photoelectron spectroscopy (XPS) (fig. S5). The capsules observed by AFM, SEM and TEM (Fig. 1, C to E), had folds and creases because these measurements were performed on dried samples. Different-sized templates $(D=120 \mathrm{~nm}, 840 \mathrm{~nm}, 3.6 \mu \mathrm{m}$, and $10 \mu \mathrm{m})$ can be exploited for capsule preparation (Fig. 1, F to I). Ellipsoidal PS templates, prepared by stretching spherical PS particles above their glass transition temperature, were also used to obtain ellipsoidal capsules (Fig. 1, J and K). From AFM height analysis, the single-wall thickness of the capsules was determined to be half of the minimum height of the collapsed flat regions $(10.4 \pm 0.6 \mathrm{~nm})$. The Young's modulus $\left(E_{Y}\right)$ of the $\mathrm{D}=3.6 \mu \mathrm{m}$ capsules was estimated to be $1.0 \pm 0.2 \mathrm{GPa}$ by AFM force measurements (fig. S6). This $E_{Y}$ is at the high end of the range observed for layer-by-layer (LbL) polyelectrolyte capsules $(10-1000 \mathrm{MPa})$ (17). Several groups have reported LbL capsules fabricated from TA and other polymers $(18,19)$. For example, LbL capsules of TA/poly $(N$-vinylpyrrolidone) (PVPON) exhibit a bilayer thickness of $1.0-2.2 \mathrm{~nm}$ depending on the molecular weight of the PVPON (19). The Fe $\mathrm{III}^{\mathrm{II}} \mathrm{TA}$ film, obtained through the one-step assembly, is thicker than four bilayers of TA/PVPON obtained through multi-step LbL assembly, demonstrating the efficiency of the one-step process. Analogous to LbL assembly, the thickness of $\mathrm{Fe}^{\mathrm{III}} / \mathrm{TA}$ films can be further increased by simply repeating the rapid coating procedure (figs. S7 and S8).

The effect of TA and $\mathrm{FeCl}_{3} \cdot 6 \mathrm{H}_{2} \mathrm{O}$ concentrations (hereafter denoted as [TA] and $\left[\mathrm{FeCl}_{3} \cdot 6 \mathrm{H}_{2} \mathrm{O}\right]$, respectively) on the resulting film thickness and morphology were investigated by AFM using $\mathrm{D}=3.6 \mu \mathrm{m}$ PS templated capsules. When [TA] was kept constant at $0.40 \mathrm{mg} \mathrm{mL}^{-1}$ $(0.24 \mathrm{mM})$, capsules were obtained over a $\left[\mathrm{FeCl}_{3} \cdot 6 \mathrm{H}_{2} \mathrm{O}\right]$ range of 0.06 to $0.20 \mathrm{mg} \mathrm{mL}^{-1}$ (0.22 to $0.74 \mathrm{mM}$ ), approximately corresponding to molar ratios of $1: 1$ to $3: 1$ between $\mathrm{Fe}^{\mathrm{III}}$ and TA. The resulting stoichiometries in the capsule walls were determined by XPS (fig. S5) to be $\mathrm{Fe}^{\mathrm{III}}$ :TA = ca. $1: 4,1: 3$, and $1: 2$ for feed $\left[\mathrm{FeCl}_{3} \cdot 6 \mathrm{H}_{2} \mathrm{O}\right]$ of $0.06,0.12$, and $0.20 \mathrm{mg} \mathrm{mL}^{-1}$, respectively. This demonstrates that the feed concentrations influence the capsule stoichiometries. Above and below $\left[\mathrm{FeCl}_{3} \cdot 6 \mathrm{H}_{2} \mathrm{O}\right]=0.06-0.20 \mathrm{mg} \mathrm{mL}^{-1}$, aggregated capsules and few capsules were formed, respectively. In the absence of $\mathrm{Fe}^{\mathrm{III}}$, no capsules were formed. $\mathrm{As}\left[\mathrm{FeCl}_{3} \cdot 6 \mathrm{H}_{2} \mathrm{O}\right]$ was increased in 
this concentration range, the $\mathrm{Fe}^{\mathrm{III}} / \mathrm{TA}$ film became thicker, from $7.7 \pm 0.4$ to $11.9 \pm 1.2 \mathrm{~nm}$, and exhibited increased roughness (fig. S9). Increasing the amount of Fe ${ }^{\mathrm{III}}$ to three molar equivalents of TA resulted in capsules that had a grainy surface because of the excess Fe ${ }^{\text {III }}$ (fig. S9A). Values of RMS roughness (300 $\mathrm{nm}$ by $300 \mathrm{~nm}$, fold-free flat region) were $1.3 \pm 0.1,1.6 \pm 0.1$ and $7.7 \pm$ $0.4 \mathrm{~nm}$ for $\left[\mathrm{FeCl}_{3} \cdot 6 \mathrm{H}_{2} \mathrm{O}\right]$ of $0.06,0.10$ and $0.20 \mathrm{mg} \mathrm{mL}$, respectively. In contrast to these observations based on $\mathrm{Fe}^{\mathrm{III}}$, [TA] had minimal impact upon film assembly. Capsules with constant film thickness and roughness were obtained throughout a concentration range of [TA] $=$ 0.10 to $1.80 \mathrm{mg} \mathrm{mL}^{-1}(0.06$ to $1.06 \mathrm{mM})$, when $\left[\mathrm{FeCl}_{3} \cdot 6 \mathrm{H}_{2} \mathrm{O}\right]$ was fixed at $0.10 \mathrm{mg} \mathrm{mL}^{-1}(0.37$ $\mathrm{mM}$ ) (fig. S10). These results suggest that TA was relatively in higher excess than $\mathrm{Fe}^{\mathrm{III}}$ under these conditions, and that $\mathrm{Fe}^{\mathrm{III}}$, and not TA, influenced the film thickness.

To further investigate the mechanism of the $\mathrm{Fe}^{\mathrm{III}} / \mathrm{TA}$ film formation, polyethyleneimine (PEI)-coated PS templates were used for capsule preparation. The PEI coating changed the zetapotential of the templates from negative $(-27.4 \pm 2.8 \mathrm{mV})$ to positive $(36.9 \pm 5.6 \mathrm{mV})$. Capsules were still formed with these positively charged templates, indicating that the surface charge is not an important factor for film deposition. We also determined the zeta-potential after incubating the bare PS particles with either TA or $\mathrm{FeCl}_{3}$. The adsorption of TA reduced the zetapotential value to $-39.4 \pm 3.6 \mathrm{mV}$, while the value was slightly changed after incubation with $\mathrm{FeCl}_{3}(-33.1 \pm 4.7 \mathrm{mV})$. Furthermore, rapid surface-adherence and formation of a TA layer on the template particle surface were confirmed by adsorption experiments (fig. S11). Catecholfunctionalized molecules and their derivatives have a high affinity for a wide variety of substrates with different surface charges $(4,20)$. Thus, it is most likely that the free TA or small $\mathrm{Fe}^{\mathrm{III}} / \mathrm{TA}$ complexes initially adsorb onto the template surface and are subsequently cross-linked by further $\mathrm{Fe}^{\mathrm{III}}$ complexation. The increase in the cross-linker concentration causes the attraction of more TA to the initially formed films, making them thicker. Film growth is completed when free $\mathrm{Fe}^{\mathrm{III}}$ in the bulk solution is consumed. Excess $\mathrm{Fe}^{\mathrm{III}}$ induces aggregation of $\mathrm{Fe}^{\mathrm{III}} / \mathrm{TA}$ complexes in the bulk solution. These small aggregates subsequently bind to the surface, leading to an increased roughness of the capsule films (fig. S12). Unlike thin film formation using dopamine self-polymerization (4), this study relies on the complexation of TA with $\mathrm{Fe}^{\mathrm{III}}$ through coordination bonds, which allows the films to form rapidly and disassemble in response to $\mathrm{pH}$ (see below).

To show the versatility of this method, various planar and particulate substrates including glass, gold (Au), polydimethylsiloxane (PDMS), poly(lactic-co-glycolic acid) (PLGA), melamine-formaldehyde resin $(\mathrm{MF})$, low-molecular-weight PDMS emulsion, silica $\left(\mathrm{SiO}_{2}\right)$, aminated $\mathrm{SiO}_{2}$, cetyltrimethylammonium bromide-capped $\mathrm{Au}$ nanoparticles ( $\mathrm{Au}$ NPs), calcium carbonate $\left(\mathrm{CaCO}_{3}\right)$, Escherichia coli (E. coli), and Staphylococcus epidermidis (S. epidermidis) with various surface properties (anionic, neutral and cationic) were coated with the Fe $\mathrm{F}^{\mathrm{III}} / \mathrm{TA}$ films (Fig. 2). The color and zeta-potential values (Fig. 2, A to D) changed after the coating in all cases, demonstrating that $\mathrm{Fe}^{\mathrm{III}} / \mathrm{TA}$ films can be formed on a wide variety of substrates. Fig. $2 \mathrm{E}$ and fig. S13A show protein and rhodamine $\mathrm{B}$ loaded $\mathrm{CaCO}_{3}$ coated with $\mathrm{Fe}$ III/TA films, respectively. The replica particles were obtained by filling mesoporous $\mathrm{CaCO}_{3}$ particles with $\mathrm{Fe}^{\mathrm{III}} / \mathrm{TA}$ complexes and dissolving the $\mathrm{CaCO}_{3}$ cores (fig. S13, B to E). After the coating, a $\mathrm{Fe}^{\mathrm{III}} / \mathrm{TA}$ shell layer was visible around the Au NP core (Fig. 2, F and G, fig. S13F). Magnetic $\mathrm{Fe}_{3} \mathrm{O}_{4}$ nanoparticles were encapsulated by coating low-molecular-weight PDMS emulsion templates loaded with $\mathrm{Fe}_{3} \mathrm{O}_{4}$ nanoparticles (fig. S13G). Subsequent removal of the emulsion by ethanol produced magnetically active Fe ${ }^{\mathrm{III}} / \mathrm{TA}$ capsules (Fig. 2, $\mathrm{H}$ and I). 
The coordination between $\mathrm{Fe}^{\mathrm{III}}$ and $\mathrm{TA}$ is $\mathrm{pH}$-dependent, and the obtained capsules exhibit $\mathrm{pH}$-dependent disassembly. The color of the capsule suspension was different at varying $\mathrm{pH}$ (Fig. 3A). The suspension was colorless at $\mathrm{pH}<2$, blue at $3<\mathrm{pH}<6$, and red at $\mathrm{pH}>7$. This color change is consistent with observations for analogous $\mathrm{Fe}^{\mathrm{III}} /$ catechol complexes $(21$, 22), which can be attributed to the transition between the mono-, bis- and tris-complex states (Fig. 3B). At pH 2.0, the Fe $\mathrm{F}^{\mathrm{III}} / \mathrm{TA}$ capsules shrunk immediately (fig. S14) and were disassembled afterward. At low $\mathrm{pH}$, most of the hydroxyl groups are protonated, which leads to rapid de-crosslinking and disassembly of the films. Even above $\mathrm{pH} 3.0, \mathrm{Fe}^{\mathrm{III}} / \mathrm{TA}$ capsules disassembled. Fig. $3 \mathrm{C}$ shows the disassembly kinetics of the $\mathrm{Fe}^{\mathrm{III}} / \mathrm{TA}$ capsules. At $\mathrm{pH} 3.0$, all of the capsules had disassembled in $4 \mathrm{~h}$, while at $\mathrm{pH} 4.0,6$ days incubation was required to disassemble the majority of the capsules. In contrast, $c a .70 \%$ and $90 \%$ of the capsules still remained intact after 10 days incubation at $\mathrm{pH} 5.0$ and $\mathrm{pH} 7.4$, respectively. The stability constants of $\mathrm{Fe}^{\mathrm{III}} / \mathrm{TA}$ are $1.5 \times 10^{5}$, $3.4 \times 10^{9}, 2.8 \times 10^{17}$ at $\mathrm{pH} 2,5,8$, respectively (23). Additionally, we carried out AFM experiments after incubation at $\mathrm{pH} 5.0$ (fig. S15). The films became thinner $(6.0 \pm 1.4 \mathrm{~nm})$ and rougher, confirming the gradual disassembly of the $\mathrm{Fe}^{\mathrm{III}} / \mathrm{TA}$ films. Ethylenediaminetetraacetic acid (EDTA) accelerated the disassembly because of its strong affinity for Fe ${ }^{\mathrm{III}}$ (Fig. 3C).

The cytotoxicity of Fe ${ }^{\text {III }} / \mathrm{TA}$ capsules was shown to be negligible (fig. S16). Coupled with their $\mathrm{pH}$-sensitive disassembly profile, $\mathrm{Fe}^{\mathrm{III}} / \mathrm{TA}$ capsules have potential biomedical application, because of the varying $\mathrm{pH}$ in different parts of the body, e.g. blood ( $\mathrm{pH} 7.4)$, stomach $(\mathrm{pH} 1.0-$ $3.0)$, duodenum ( $\mathrm{pH} 4.8-8.2$ ), etc. (24). Iron tannate has been historically recognized as an ink (25) and a corrosion-resistant layer for steel (15). It had also been used for dyeing teeth black, and consequently preventing cavities, in the old Japanese custom called 'Ohaguro' (26). The general applicability of this technique was further demonstrated by using different metals and another polyphenol (figs. S17 and S18). The simple preparation and biologically relevant physicochemical properties of the metal-polyphenol films provide a platform for the engineering and assembly of advanced materials for potential use in a range of applications.

\section{References and Notes:}

1. G. Decher, Science 277, 1232 (1997).

2. F. Caruso, R. A. Caruso, H. Möhwald, Science 282, 1111 (1998).

3. D. Y. Ryu, K. Shin, E. Drockenmuller, C. J. Hawker, T. P. Russell, Science 308, 236 (2005).

4. H. Lee, S. M. Dellatore, W. M. Miller, P. B. Messersmith, Science 318, 426 (2007).

5. A. Betard, R. A. Fischer, Chem. Rev. 112, 1055 (2012).

6. Y. Yan, J. B. Huang, Coord. Chem. Rev. 254, 1072 (2010).

7. A. Hatzor et al., J. Am. Chem. Soc. 120, 13469 (1998).

8. M. Wanunu et al., J. Am. Chem. Soc. 127, 17877 (2005).

9. R. Kaminker et al., J. Am. Chem. Soc. 132, 14554 (2010).

10. L. Motiei et al., Langmuir 27, 1319 (2011).

11. R. Makiura et al., Nat. Mater. 9, 565 (2010).

12. M. Hanke et al., Langmuir 28, 6877 (2012).

13. See supplementary materials on Science Online.

14. T. Mori et al., J. Biol. Chem. 287, 6912 (2012).

15. T. K. Ross, R. A. Francis, Corros. Sci. 18, 351 (1978).

16. C. S. Peyratout, L. Dahne, Angew. Chem. Int. Ed. 43, 3762 (2004).

17. O. I. Vinogradova, O. V. Lebedeva, B. S. Kim, Annu. Rev. Mater. Res. 36, 143 (2006).

18. T. Shutava, M. Prouty, D. Kommireddy, Y. Lvov, Macromolecules 38, 2850 (2005). 
19. V. Kozlovskaya, E. Kharlampieva, I. Drachuk, D. Cheng, V. V. Tsukruk, Soft Matter 6, 3596 (2010).

20. Q. Ye, F. Zhou, W. M. Liu, Chem. Soc. Rev. 40, 4244 (2011).

21. H. Xu et al., ACS Macro Lett. 1, 457 (2012).

22. N. Holten-Andersen et al., Proc. Natl. Acad. Sci. U. S. A. 108, 2651 (2011).

23. S. Sungur, A. Uzar, Spectrochim. Acta Part A 69, 225 (2008).

24. D. Schmaljohann, Adv. Drug Delivery Rev. 58, 1655 (2006).

25. V. Rouchon et al., Anal. Chem. 83, 2589 (2011).

26. Y. Tanizawa, K. Sawamura, T. Suzuki, J. Chem. Soc. Faraday Trans. 86, 1071 (1990).

27. J. A. Champion, S. Mitragotri, Proc. Natl. Acad. Sci. U. S. A. 103, 4930 (2006).

28. C. I. Zoldesi, A. Imhof, Adv. Mater. 17, 924 (2005).

29. J. Cui et al., Adv. Funct. Mater. 20, 1625 (2010).

30. H. Imai, N. Tochimoto, Y. Nishino, Y. Takezawa, Y. Oaki, Cryst. Growth Des. 12, 876 (2012).

Acknowledgments: The Australian Research Council is acknowledged for support under the Federation Fellowship (FF0776078) (F.C.), Australian Laureate Fellowship (FL120100030) (F.C.), Discovery Project (DP0877360) (F.C.), Future Fellowship (FT120100564) (G.K.S.), and Super Science Fellowship (FS110200025) (J.C. and F.C.) schemes. H.E. thanks the Japan Society for the Promotion of Science (JSPS) for a Postdoctoral Fellowship for Research Abroad. The data presented in this paper are given in the main text and in the supplementary materials. Dr. Xiaofei Duan (Surface and Chemical Analysis Network, The University of Melbourne) is thanked for assistance with XPS analysis. The authors declare no conflict of interest. 


\section{Figure Captions}

Fig. 1. Film formation. Fe $\mathrm{III}_{\mathrm{T}} \mathrm{T}$ films prepared on PS substrates with various shapes (planar, spherical and ellipsoidal) and sizes $(\mathrm{D}=120 \mathrm{~nm}-10 \mu \mathrm{m})$. (A) Photograph of PS slides before (top) and after (bottom) $\mathrm{Fe}^{\mathrm{III}} / \mathrm{TA}$ coating. (B-K) Microscopy images of $\mathrm{Fe}^{\mathrm{III}} / \mathrm{TA}$ capsules. DIC $(\mathbf{B}, \mathbf{I}, \mathbf{J})$, AFM (C), TEM (E,F,G,K), SEM (D), and fluorescent microscopy (H) images.

Fig. 2. Fe $\mathrm{III} / \mathrm{TA}$ coating on various substrates. (A-C) Photograph of planar substrates before (upper) and after (lower) Fe $\mathrm{Fe}^{\mathrm{III}} / \mathrm{TA}$ coating. Glass (A), Au (B), PDMS (C). (D) Zeta potential values of particulate substrates in water before and after the Fe $\mathrm{F}^{\mathrm{III}} / \mathrm{TA}$ coating. The results are average values with standard deviations (mean \pm S.D.). (E) A confocal laser scanning microscopy image of protein-loaded $\mathrm{CaCO}_{3}$ particles (red) coated with $\mathrm{Fe}^{\mathrm{III}} / \mathrm{TA}$ films (green) $(\mathbf{F , G})$ TEM images of Au NPs non-coated $(\mathbf{F})$ and coated $(\mathbf{G})$ with $\mathrm{Fe}^{\mathrm{III}} / \mathrm{TA}$ films. $(\mathbf{H}, \mathbf{I})$ Photographs of $\mathrm{Fe}^{\mathrm{III}} / \mathrm{TA}$ capsules loaded with $\mathrm{Fe}_{3} \mathrm{O}_{4}$ nanoparticles dispersed in water before $(\mathbf{H})$ and after (I) applying a magnet.

Fig. 3. pH-responsive disassembly of $\mathrm{Fe}^{\mathrm{III}} / \mathrm{TA}$ capsules. (A) UV-Vis absorption spectra of spherical $\mathrm{Fe}^{\mathrm{III}} / \mathrm{TA}$ capsule dispersions $\left(\mathrm{D}=3.6 \mu \mathrm{m}, 4.0 \times 10^{7}\right.$ capsules $\left.\mathrm{mL}^{-1}\right)$ at various $\mathrm{pH}$. Inset is a photograph of the capsule dispersions at the indicated $\mathrm{pH}$. (B) $\mathrm{pH}$-dependent transition of dominant $\mathrm{Fe}^{\mathrm{III}} / \mathrm{TA}$ complexation state. $\mathrm{R}$ represents the remainder of the TA molecule. (C) Plot of remaining capsule population (\%) against time. The results are average values with standard deviations from three independent measurements (mean \pm S.D.). 